\title{
Body Weight Distribution Over the Hands throughout the Duration of a Continuous Push-up Bout
}

\author{
Jennifer K Hewit*, Daniel A Jaffe, Todd A Crowder and Alexander J Bedard \\ Department of Physical Education, Human Performance Laboratory, USA
}

*Corresponding author: Jennifer Hewit, Department of Physical Education, United States Military Academy, 727 Brewerton Rd, West Point, NY 10996, USA

Submission: 眥 November 05, 2018; Published: 眥 January 22, 2019

\begin{abstract}
Background: A great deal of research has addressed various aspects of push-up performance including joint loading, muscle activity, shoulder girdle stabilization, etc. However less attention has been given to the distribution of body weight (BW) throughout the exercise bout. Therefore, the purpose of this study was to assess the distribution of body weight (BW) over the hands for males and females throughout a 1-minute continuous pushup bout. A second research question aimed to investigate whether a 6-week push-up specific training program was an effective means of improving BW distribution throughout such an exercise bout.
\end{abstract}

Methods: A total of 19 females and 22 males participated in this study. Pre-and post-testing consisted of a 1-minute continuous push-up bout with each hand placed on am individual force plate. Average peak force out from each hand was analyzed at the beginning and end of the bout. The pre- and post-tests were separated by a 6-week push-up specific training intervention, which was performed 3 times per week by all participants.

Results: For both the pre- and post-test assessments, the percent BW (\%BW) positioned over the force plates was significantly greater at the start compared to the end of the 1 -min bouts $(\mathrm{t}(37)=10.50, \mathrm{p}<0.00, \mathrm{~d}=1.21$ and $\mathrm{t}(40)=9.09, \mathrm{p}<0.00, \mathrm{~d}=1.06$, respectively). Additionally, significantly more $\mathrm{BW}$ was positioned over the force plates at the end of the post-test when compared to that of the pre-test $(t(37)=-1.83, p=0.03, d=0.21)$. Both males and females significantly decreased the \%BW positioned over the force plates throughout both the pre- and post-tests (males: $\mathrm{t}(17)=13.99, \mathrm{p}<0.00, \mathrm{~d}=3.06$, and $\mathrm{t}(18)=13.71, \mathrm{p}<0.00, \mathrm{~d}=3.35$, respectively; females: $\mathrm{t}(19)=6.90, \mathrm{p}<0.00, \mathrm{~d}=1.31$, and $\mathrm{t}(21)=5.52, \mathrm{p}<0.00, \mathrm{~d}=0.76)$.

Conclusion: Body weight distribution was observed to decrease significantly for both genders throughout the push-up bouts during both pre- and post-tests. While a trend was observed to indicate that an exercise-specific training program results in a greater distribution of BW over the hands throughout the bout, a longer training program (e.g. 12-16 weeks) will likely result in a stronger trend and is recommended for future research.

Keywords: Prevention and health promotion models; Childhood and adolescence

\section{Introduction}

The push-up exercise is commonly used as a test of upper body muscular endurance, with the total number or repetitions (reps) completed over a set duration of time being recorded [1]. This assessment tool is most commonly used by various military branches in the United States as a bi-annual measurement of physical fitness readiness. According to the U.S. Army guidelines, both genders are required to perform the exercise by pivoting on the toes as opposed to performing the push-up from a modified kneeling position. By allowing only the hands and toes to contact the ground throughout the assessment, the individual's entire body weight must be distributed about these two points of contact.

Previous research has determined that anywhere from 65$69 \%$ of body weight is supported through the hands during the traditional push-up (i.e. pivoting on the toes) while in the starting position where the elbows are fully extended [2-5]. However, these studies required participants to perform a total of only 3-5 reps for data collection. While this information is highly valuable with regards to determining exercise progressions, it leaves additional questions related to compensational strategies adopted under fatigued conditions yet to be answered. Muscular endurance has been defined as the ability to repeatedly exert submaximal force over a given period of time or number of repetitions [6]. For an exercise like the push-up, where bodyweight is being supported by the individual throughout the duration of the exercise (e.g. 1-2 minutes), it is reasonable to assume that adjustments in body positioning are likely to be adopted as the muscles begin to tire. However, there is a paucity of research investigating whether the percent of body weight supported by the hands changes significantly throughout the entirety of a muscular endurance push-up assessment. 
According to the U.S. Army guidelines, throughout the pushup assessment participants may briefly rest in an altered position where the hips and knees are flexed but not touching the ground [1]. However, no more than $50 \%$ of the participant's body weight can be supported by the legs at any time. Additionally, the proper starting position (i.e. elbows fully extended and a straight-line body position from head to toe) must be assumed before continuing with the performance. Assessing the percent body weight supported by the hands at the beginning and end of a push-up assessment has the potential to provide valuable information regarding compensational movement patterns as well as their possible implications for muscle recruitment and joint stresses. Therefore, the first aim of this research was to investigate whether the percent body weight (\%BW) supported by the hands changed significantly over the course of a 1-minute continuous push-up bout. It was hypothesized that as the participants began to tire, they would gradually redistribute their BW so that a greater proportion was supported by the legs. It was further hypothesized that by the end of the 1-minute bout, greater than $50 \%$ of their BW would be supported by their legs.

This study also sought to assess whether a relatively short movement-specific training program would be an effective means of improving BW distribution over the course of the push-up assessment. It was hypothesized that after implementing a 6-week push-up specific training program, participants would be able to maintain greater than $50 \%$ of their BW through their hands at the end of the 1-minute assessment.

Finally, the investigators were interested in whether the \% BW supported by the hands was significantly different for males compared to that of females. It was hypothesized that females would support less of their body weight by through their hands throughout the bout, with greater than $50 \%$ of BW being supported by the legs at the end.

\section{Methods}

\section{Participants}

A total of 41 recreationally active males $(n=19)$ and females $(n=22)$ volunteered to participate in this study. It is important to note that all subjects reported that they perform push-ups on a regular basis and were familiar with the 1-minute pushup assessment. Subject characteristics are presented in Table 1. Participants were allowed to continue with their regular physical training throughout the study but were asked to document their workouts during the 6-week training program. Participants were free of injury throughout the entirety of the study and were made aware of all testing procedures prior to participation. Prior to participation, an informed written consent was obtained from each participant. All testing procedures were approved by the Human Research Protection Program before commencing the study.

Table 1: Subject characteristics by gender and training group.

\begin{tabular}{|c|c|c|c|c|}
\hline \multicolumn{3}{|c|}{ Males Mean (SD) } & \multicolumn{2}{|c|}{ Females Mean (SD) } \\
\hline $\mathbf{N}$ & \multicolumn{2}{|c|}{19} & \multicolumn{2}{|c|}{22} \\
\hline Program & REP & CAD & REP & CAD \\
\hline $\mathrm{n}$ & 7 & 12 & 9 & 13 \\
\hline Age (years) & $23.0(7.0)$ & $22.7(7.4)$ & 31.7 (13.7) & $29.9(12.2)$ \\
\hline Height (m) & $1.74(0.47)$ & $1.76(0.64)$ & $1.51(0.33)$ & $1.66(0.61)$ \\
\hline Weight (kg) & $71.8(8.3)$ & $83.4(12.1)$ & $65.7(12.5)$ & $63.6(9.4)$ \\
\hline
\end{tabular}

\section{Experimental design}

This is an interventional study design, investigating the effects of an exercise-specific training protocol on body weight distribution. Participants reported to an initial baseline testing session as well as an identical post-test session. Participants also reported to the lab and were supervised by one of the researchers for all training sessions.

\section{Pre and post testing set up}

Two portable force plates $(1000 \mathrm{~Hz})$ (Vernier, Beaverton, OR) were placed on the floor in front of a wooden platform raised up to be flush with the surface of the force plates. Participants were allowed to position the force plates specific to their hand width preference when performing push-ups. Force output from each hand was collected for the entirety of the 1-minute push-up bout.

\section{Experiment procedures}

Upon arrival to the pre-test session, the age, height and body mass was recorded for each participant. Both force plates were zeroed once they were positioned to the comfort of the participant.
A 5-minute non-standardized warm-up period was allowed before commencing the 1-minute bout. The participants were given a countdown prior to the start of the push-up bout in the following increments: 1 minute, 30 seconds, 15 seconds, 5, 4, 3, 2, and 1 . During the assessment, participants were allowed to rest briefly in the upward pike position as needed (as per U.S. Army regulations). Participants were also allowed to reposition their hands on the force plates as needed, by sliding them across the surface. Following the 1-minute bout, participants were allowed to cool down on their own prior to leaving the lab.

Participants were given their 6-week training program upon arrival to their first training session. Participants were required to perform the progressive push-up training program 3 times per week for 6 consecutive weeks. Compliance to the training program was documented by a sign-in sheet. Each participant was supervised by one of the researchers as they performed their program. Pushup body position was monitored and corrected as needed by the investigator, emphasizing the following characteristics presented in previous literature: 
A. Hands positioned directly below the chest.

B. Upper arm abduction to approximately 45 degrees from the torso when in the maximum elbow flexion.

C. Maintaining a straight-line body position from the head to ankles [1].

As depth of the push-ups was not of paramount interest for this particular study, participants were encouraged to lower as far as they could for each rep while maintaining the hand and body

Table 2: Example of the 6 weeks of the push-up specific training program.

\begin{tabular}{|c|c|c|c|}
\hline Pre-test Push-up Score: 50 & Day 1 & Day 2 & Day 3 \\
\hline Week $1 \& 2$ & $5 \times 5$ & $5 \times 5$ & $5 \times 5$ \\
\hline Emphasis: Eccentric & Rest: & Rest: & Rest: \\
\hline Cadence: $5 / x / x$ & 0.041666667 & $: 45$ & $: 30$ \\
\hline Week: $3 \& 4$ & $5 \times 8$ & $5 \times 8$ & $5 \times 8$ \\
\hline Emphasis: Isometric & Rest: & Rest: & Rest: \\
\hline Cadence: $2 / 3 / x$ & 0.041666667 & $: 45$ & $: 30$ \\
\hline Week $5 \& 6$ & $5 \times 10$ & $5 \times 10$ & $5 \times 10$ \\
\hline Emphasis: Concentric & Rest: & Rest: & Rest: \\
\hline Cadence: $2 / x / 3$ & 0.041666667 & $: 45$ & $: 30$ \\
\hline
\end{tabular}

\section{Data Analysis}

For both the pre-test and post-test 1-minute push-up bouts, the $2^{\text {nd }}, 3^{\text {rd }}$ and $4^{\text {th }}$ reps (referred to as the "start") and the $4^{\text {th }}, 3^{\text {rd }}$ and $2^{\text {nd }}$ to last reps of the bout (referred to as the "end") were used for analysis. The peak vertical force output $(\mathrm{N})$ for each rep was averaged across the three start and end trials for the right and left hand. These data were then normalized by dividing each by the participant's body weight in Newtons. The normalized values were used for the statistical analysis and comparison.

\section{Statistical Analyses}

Independent $\mathrm{t}$-tests were used to determine if significant differences were present between the right and left force output values. Paired t-tests were used to determine if significant differences were present between the start and end of the pre-test as well as the post-test. Paired t-tests were also used to determine if significant differences were present between the starting values of the pre-test with that of the post-test and the ending values of the pre-test with that of the post-test.

Using Cohen's d effect sizes (ES) for all significant data, a value of 0.00 to 0.20 was considered to be a weak effect, 0.21 to 0.60 was characteristics listed above. The push-up-specific training program followed a traditional linear periodization protocol by progressively increasing the volume (i.e. volume=sets $\mathrm{x}$ reps) performed by $5-10 \%$ each week [7]. Examples the training program is presented in Table 2. Participants began the program at a specified number of repetitions based directly off of the total number of repetitions completed to standard during their pre-test. During the week following the six-week training program, participants returned to the lab for their post-test 1-minute push-up assessment, wherein the procedures outlined for the pre-test were duplicated. 
Table 3: Means and standard deviations (SD) of force output normalized to body weight throughout the 1-minute pushup bout for both the pre-and post-tests.

\begin{tabular}{|c|c|c|c|}
\hline & Start Mean (SD) & End Mean (SD) & P-Value (Cohen's d) \\
\hline Pre & $59.3 \%(13.8)$ & $46.1 \%(6.9)$ & $<0.00^{*}-1.21$ \\
\hline Post & $58.9 \%(13.3)$ & $47.6 \%(7.0)$ & $<0.00^{*}-1.06$ \\
\hline p-value (Cohen's d) & 0.28 & $0.03 *-0.21$ & \\
\hline
\end{tabular}

*Indicates statistical significance at the 0.05 alpha level.

Both males and females significantly decreased the \%BW positioned over the force plates throughout both the pre- and post-tests (males: $\mathrm{t}(17)=13.99, \mathrm{p}<0.00, \mathrm{~d}=3.06$, and $\mathrm{t}(18)=13.71$, $\mathrm{p}<0.00, \mathrm{~d}=3.35$, respectively; females: $\mathrm{t}(19)=6.90, \mathrm{p}<0.00, \mathrm{~d}=1.31$, and $\mathrm{t}(21)=5.52, \mathrm{p}<0.00, \mathrm{~d}=0.76)$ Table 4 . However, there was no significant difference in \%BW over the force plates at the start or end between the two testing sessions for either gender. Males

Table 4: Means and standard deviations (SD) of the force output normalized to body weight throughout the 1-minute push-up bout for the pre- and post-tests by gender.

\begin{tabular}{|c|c|c|c|c|c|c|}
\hline & \multicolumn{2}{|c}{ Males } & \multicolumn{2}{c|}{ Females } \\
& Start Mean (SD) & End Mean (SD) & $\begin{array}{c}\text { P-value } \\
\text { (Cohen's d) }\end{array}$ & Start Mean (SD) & End Mean (SD) & $\begin{array}{c}\text { P-value (Cohen's } \\
\text { d) }\end{array}$ \\
\hline Pre & $71.6 \%(7.9)$ & $52.1 \%(4.2)$ & $<0.00^{*}-3.06$ & $48.8 \%(7.7)$ & $40.9 \%(3.7)$ & $<0.00^{*}-1.31$ \\
\hline Post & $70.5 \%(6.5)$ & $52.7 \%(3.8)$ & $<0.00^{*}-3.35$ & $48.9 \%(8.8)$ & $43.2 \%(6.1)$ & $<0.00^{*}-0.76$ \\
\hline $\begin{array}{c}\text { p-value (Cohen's } \\
\text { d) }\end{array}$ & 0.29 & 0.55 & & 0.86 & 0.08 & \\
\hline
\end{tabular}

*Indicates statistical significance at the 0.05 alpha level.

\section{Discussion}

This study investigated the distribution of BW throughout a 1-minute push-up assessment and whether 6-weeks of push-up specific training would improve participants' ability to maintain a greater \%BW over their hands throughout the entirety of the bout. The results of this study support our first two hypotheses, in that BW distribution decreased significantly for all participants from the beginning to the end of the bout, ultimately ending with greater than $50 \%$ of the BW (54\%) being supported by the legs for the group as a whole. Similarly, when comparing participants by gender, both males and females significantly decreased the \%BW that was being supported by the upper body by the end of the bout (a decrease of 19\% and 6\% for males and females, respectively). While there has been a paucity of research investigating the changes in BW distribution over the course of a muscular endurance pushup assessment, several studies have assessed the initial \%BW for males in the starting position of the traditional push-up. The reported averages (64-72\%BW) are consistent with the values for males in the current study, as assessed at the beginning of both the pre-and post-test bouts $[2-4,9,10]$. initially supported approximately $70 \%$ of their BW through their hands and decreased to approximately $52 \%$ by the end of the bout during both the pre- and post-test session. Females initially supported approximately $48 \%$ of their BW through their hands and decreased to less than $45 \%$ by the end of the bout during both the pre- and post-test sessions. 
force plate may be more directly related to the natural distribution of muscle mass in females as opposed to intentionally supporting more BW with the legs during the current study.

\section{Conclusion}

As participants began to fatigue, a greater proportion of their body weight was supported by their lower body. This ultimately decreased the demand of the upper body musculature, thereby allowing the participant to continue with the exercise under a condition of fatigue. While there was significantly greater $\% \mathrm{BW}$ positioned over the hands at the end of the bout following 6-weeks of training, the inference of this finding is limited as the effect size was trivial. While only 6 weeks of training in the current study has begun to indicate a trend for maintaining more than $50 \%$ of BW over the hands throughout the bout, it is likely that a longer training program (e.g. 12-16 weeks) will elicit a stronger trend. Therefore, it is recommended that future research investigate BW distribution over the hands following a push-up specific training program that is no less than 12 weeks in duration.

\section{References}

1. Army US (2013) Army physical fitness test (APFT). US Department of the Army, Washington, USA.

2. Ebben W, Wurm B, Zanden VT, Spadavecchia M, Durocher J (2011) Kinetic analysis of several variations of push-ups. J Strength Cond Res 25(10): 2891-2894

3. Gouvali M, Boudolos K (2005) Dynamic and electromyographical analysis in variants of push-up exercise. J Strength Cond Res 19(1): 146-151.
4. Mier C, Amasay T, Capehart S, Garner H (2014) Differences between men and women in percentage of body weight supported during the push-up exercise. International Journal of Exercise Science 7(2): 161-168.

5. Suprak D, Bohannon J, Morales G, Stroschein J, Juan SJ (2013) Scapular kinematics and shoulder elevation in a traditional push-up. J Athl Train 48(6): 826-835.

6. Medicine AC (2014) Health-related physical fitness testing and interpretation. In: Pescatello L (Ed.), ACSM's Guidelines for exercise testing and prescription $\left(9^{\text {th }}\right.$ edn), Lippincott Williams \& Wilkins, Baltimore, USA, p. 99.

7. Bompa T, Haff G (2009) Linear loading. In: Bahrke M (Ed.), Periodization: Theory and methodology of training ( $5^{\text {th }}$ edn), Human Kinetics, Champaign, IL, USA, pp. 46-47.

8. Urdan T (2007) Statistical significance, effect size, and confidence intervals statistics in plain english. Routledge, New York, USA.

9. Amasay T, Mier C, Foley K, Carswell T (2016) Gender differences in performance of equivalently loaded push-up and bench-press exercises. The Journal of Sport 5(1): 46-63.

10. Suprak D, Dawes J, Stephenson M (2011) The effect of position on the percentage of body mass supported during traditional and modified push-up variants. J Strength Cond Res 25(2): 497-503.

11. Abe T, Kearns C, Fukunaga T (2003) Sex differences in whole body skeletal muscle mass measured by magnetic resonance imaging and its distribution in young Japanese adults. Br J Sports Med 37(5): 436-440.

12. Janssen I, Heymsfield S, Wang Z, Ross R (2000) Skeletal muscle mass and distribution in 468 men and women aged 18-88 yr. J Appl Physiol 89(1): 81-88.
Creative Commons Attribution 4.0 International License

For possible submissions Click Here

\section{Submit Article}

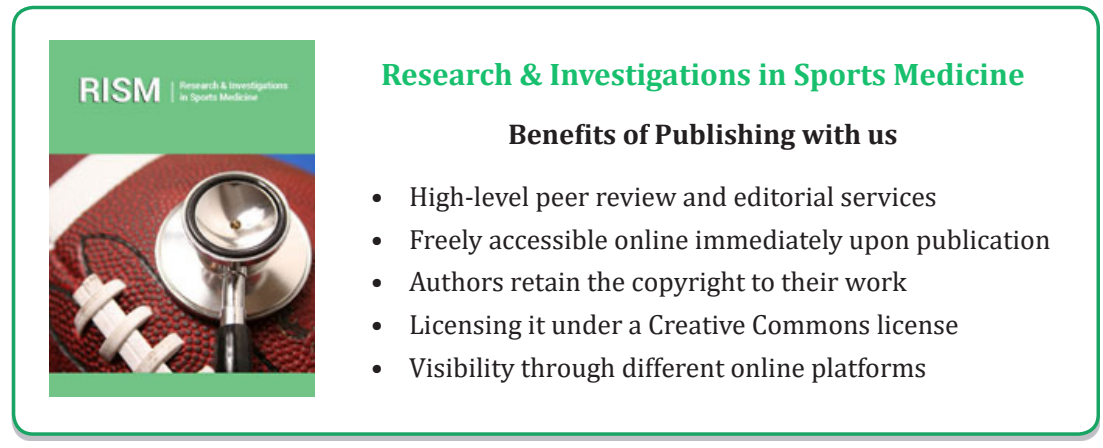

